\title{
A modalidade Veridictória na articulação do suspense
}

\author{
The Veridictoria modality in the articulation of the suspense
}

\author{
Leliane Regina Ortega ${ }^{1}$ \\ Marcelo Nicomedes dos Reis Silva Filho \\ Antônio Carlos Santana Souza ${ }^{3}$
}

\author{
Recebido em: 05/02/2019 \\ Aprovado em: 13/07/2019 \\ Publicado em: 30/07/2019
}

\begin{abstract}
RESUMO: O suspense, como fio condutor de algumas narrativas, mobiliza a ansiedade do leitor e por meio da tensa espera prende sua atenção até o desfecho do enredo e a revelação do inesperado. A Semiótica francesa ou greimisiana oferece subsídios, em suas fases de aprofundamento do estudo do texto, para compreendermos como a modalização do ser, especialmente por meio da modalização veridictória do segredo, auxilia essa construção tão presente em novelas, filmes, romances e em diversos tipos de narrativas. Nosso objetivo nesse trabalho é revisitar alguns conceitos da Semiótica que nos ajudem a compreender a modalização veridictória, como modo de construção do suspense por meio da estrutura modal do não parecer/ser que subsidia a formação do segredo, responsável por aguçar e prender o interesse dos leitores por toda a narrativa. Para isso nos amparamos nos estudos de Greimas e Courtés (2011), Fontanille (2011), Barros (2005), Fiorin (2000) e Silva (2011). O texto literário possui particularidades quanto a organização da linguagem capazes de estimular até os leitores mais desinteressados, por isso, faz-se necessário estudar teorias que expliquem essa organização e nos ajudem a compreender as diferentes composições literárias. Como obra literária, nos apropriaremos de Pântano de sangue de Pedro Bandeira para exemplificar e refletir sobre os conceitos estudados.
\end{abstract}

Palavras-chave: Semiótica; Modalidade Veridictória; Suspense.

ABSTRACT: Suspense, as the guiding thread of some narratives, mobilizes the anxiety of the reader and through the tense wait holds his attention until the end of the plot and the revelation of the unexpected. The French or Greimian Semiotics offers subsidies, in its phases of deepening the study of the text, to understand how the modalization of the being, especially through the veridictory modality of the secret, helps this construction so present in novels, films, novels and in diverse types of narratives. Our objective in this work is to revisit some concepts of semiotics that help us to understand veridictory modalization, as a way of constructing suspense through the modal structure of non-opinion / being that subsidizes the formation of secrecy, responsible for sharpening and arresting the interest of readers throughout the narrative. For this, we rely on the studies of Greimas and Courtés (2011), Fontanille (2011), Barros (2005), Fiorin (2000) and Silva (2011). The literary text has particularities about the organization of language capable of stimulating even the most disinterested readers, so it is necessary to study theories that explain this organization and help us understand the different literary compositions. As a literary work, we will appropriate Pedro Bandeira's Swamp of Blood to exemplify and reflect on the concepts studied.

Keywords: Semiotics; Veridictory; Modality; Thriller.

1.Graduação em Letras. Mestrado Profissional - área de Concentração: Linguagens e letramentos. Doutoranda em Letras pelo programa de Pós-Graduação Stricto Sensu em Letras - área de Concentração: Linguagem e sociedade na Universidade Estadual do Oeste do Paraná. Professora da Rede Estadual de Educação do Estado do Paraná. ORCID: 0000-0002-8614-8342 E-mail: leliortega@gmail.com

2.Graduado em Letras. Especialista em Metodologia do Ensino de Língua Inglesa. Mestrado em Letras. Doutorando no programa de pós-graduação em Letras - Linguagem e Sociedade da Universidade Estadual do Oeste do Paraná. Professor do Curso de Licenciatura em Linguagens e Códigos da Universidade Federal do Maranhão. ORCID: 0000-0002-9715-2099 E-mail: nicomedes@gmail.com

3.Graduação - Bacharelado e Licenciatura em Letras (Português/Hebraico e Respectivas Literaturas). Mestrado em Semiótica e Linguística Geral. Doutor em Letras. Pós-Doutorado em Linguística. Docente Colaborador Programa de Pós-graduação (Mestrado) em Letras da UNEMAT-Sinop. Líder do Núcleo de Pesquisa e Estudos Sociolinguístico, Dialetológicos e Discursivos do CNPq (NUPESDD-UEMS) e do Laboratório Sociolinguístico de Línguas Não-Indo-europeias e Multilinguismo do CNPq (LALIMU). ORCID: 0000-0003-4757-635X E-mail: acssuems@gmail.com 


\section{INTRODUÇÃO}

Um grupo de garotos inteligentes e corajosos, "Os Karas", diante do brutal assassinato do professor de matemática. $O$ mistério instala questões que precisam ser respondidas pelas buscas no "Pântano de sangue" e o suspense desenvolvido no enredo incita a curiosidade do leitor diante da disjunção dos sujeitos e do objeto, ou seja, da verdade.

O suspense é uma característica peculiar da literatura, pois segundo Silva "como acontecimento inesperado, suspende a duração contínua do enunciado e instaura a sua breve duração arrebatadora" (SILVA, 2011, p. 62). O mistério se desenvolve por meio de uma linguagem específica que prende a atenção do leitor/ouvinte, uma vez que, de acordo com Eagleton, "a literatura transforma e intensifica a linguagem comum, afastando-se sistematicamente da fala cotidiana" (EAGLETON, 2006, p. 3).

O objetivo desse trabalho é estudar a obra "Pântano de sangue" sob o direcionamento da semiótica, buscando compreender o suspense que envolve 0 enredo pelas vias da modalidade veridictória.

Para melhor compreendermos como o suspense se instala no texto narrativo, recorreremos aos estudos de Greimas e Courtés (2011), Fontanille (2011), Silva (2011), Barros (2005) e Fiorin (2000).

Para darmos conta do proposto, primeiramente refletiremos sobre alguns aspectos da Semiótica; a seguir discutiremos sobre a modalidade veridictória e finalmente apresentaremos algumas reflexões sobre o suspense. Sempre que possível, aspectos da obra Pântano de sangue de Pedro Bandeira será utilizado para exemplificar a parte teórica, dessa forma pretendemos entender essa narrativa sob o viés da semiótica.

\section{A SEMIÓTICA}

A semiótica francesa tem como principal representante Algirdas Julien Greimas e parte do princípio de que os textos passam por um processo de enriquecimento semântico, além de possuírem uma lógica subjacente geral. Para Barros, "a semiótica tem por objeto o texto, ou melhor procura descrever e explicar o que o texto diz e como ele faz para dizer o que diz" (BARROS, 2005, 
p. 11). Essa ciência compreende o texto como um todo de sentido, determinado pela organização ou estruturação e ainda, como um objeto de comunicação que se constitui entre um destinador e um destinatário. Ainda segundo a autora, "para construir o sentido do texto, a semiótica concebe o seu plano do conteúdo sob a forma de um percurso gerativo" (BARROS, 2005, p. 13). Esse percurso gerativo vai do simples e abstrato ao complexo e concreto e se constitui em três níveis: as estruturas fundamentais, as estruturas narrativas e as estruturas discursivas.

Os direcionamentos metodológicos propostos pela semiótica francesa ou greimasiana partem da proposição de que todo enunciado tem um sujeito da enunciação que se desdobra em um enunciador e um enunciatário pressupondo uma interlocução entre ambos. Segundo o Dicionário de semiótica de Greimas e Courtés, "entende-se por enunciado toda grandeza dotada de sentido, pertencente à cadeia falada ou ao texto escrito" (GREIMAS; COURTÉS, 2011, p. 168). Para os autores, o enunciado é o resultado da enunciação e podem existir em duas formas elementares: a) enunciados de estado, concebidos como junção que se articulam em dois termos contraditórios, conjunção e disjunção; b) enunciados de fazer, que se referem a transformação, ou seja, passagem de um estado a outro.

O enunciado que buscamos estudar, trata-se do livro "Pântano de sangue" de Pedro Bandeira e encontra-se no nível narrativo, ou seja, consiste em um enunciado narrativo modalizado pelo suspense.

De acordo com Fiorin (2000), o nível narrativo foi o mais desenvolvido pelos estudos da semiótica, onde se situa a sintaxe narrativa. $\mathrm{O}$ autor explica que,

$$
\begin{aligned}
& \text { dessa noção de enunciado narrativo decorre o fato de que é } \\
& \text { possível prever organizações hierarquizadas de enunciados. } \\
& \text { Estes se organizam em programas narrativos (um enunciado de } \\
& \text { fazer regendo um enunciado de estado), os percursos narrativos } \\
& \text { (encadeamentos lógicos de programas narrativo sem que um } \\
& \text { programa pressupõe outro) e em sequências narrativas (em que } \\
& \text { se organizam os percursos narrativos) (FIORIN, 2000, p. 173). }
\end{aligned}
$$

Para o autor a sintaxe narrativa vai do programa ao percurso e deste a sequência, trajetórias que podem ser repetidas indefinidas vezes, porém também dispõe de uma "dimensão polêmica", ou seja, a narração pode ser desenvolvida sob diferentes pontos de vista. Assim sendo, a narrativa estudada 
é narrada em terceira pessoa, mas poderia ser desenvolvida pela ótica do protagonista, o adolescente Crânio, pelo ponto de vista do antagonista, o chefe dos traficantes, ou pela ótica de qualquer outro personagem.

De acordo com Barros, "a sintaxe narrativa deve ser pensada como um espetáculo que simula o fazer do homem que transforma o mundo" (BARROS, 2005, p. 20). Para que a compreensão desse espetáculo se efetive é preciso descrevê-lo, além de determinar seus participantes e o papel que representam. Nesse sentido, a autora apresenta duas concepções de narrativa que se complementam,

narrativa como mudança de estados, operada pelo fazer transformador de um sujeito que age no e sobre o mundo em busca de valores investidos nos objetos; narrativa como sucessão de estabelecimentos e de rupturas de contratos entre um destinador e um destinatário, de que decorrem a comunicação e os conflitos entre sujeitos e a circulação de objetos (BARROS, 2005, p. 20 - grifos nossos).

Essas estruturas de narrativas propostas, envolvem tanto o percurso do sujeito em busca do objeto desejado quanto os conflitos que evidenciam os relacionamentos humanos. Para Fiorin, "a existência da semiótica é dada pela relação do sujeito com o objeto [...] um sujeito só tem existência na medida em que está em relação com um objeto" (FIORIN, 2000, p. 178). A obra estudada se caracteriza como uma narrativa que impulsiona a mudança de estados, uma vez que as ações de um grupo de jovens são impulsionadas pela ânsia de descobrir as razões que ocasionaram o assassinato de um professor, ou seja, são impelidas pelo senso de justiça.

Fontanille (2011) explica que a análise estrutural dos textos em seus primórdios concebia uma estrutura narrativa explícita ou implícita em todo tipo de texto, pois:

Quando se busca um princípio de organização global do discurso que ultrapasse a estrutura das frases, a lógica narrativa impõe-se como uma das soluções mais cômodas a adotar. Ela permite, entre outras coisas, estabelecer ligações a distância que estão, às vezes, ocultas pela segmentação e a sucessão das unidades textuais (FONTANILLE, 2011, p. 87). 
A essência dessa concepção de narrativa consistia nas noções de sujeito, anti-sujeito e objeto de valor. Segundo a descrição estrutural de Greimas, um sujeito sempre busca um objeto, uma meta que tem valor para ele, ou seja, busca entrar em conjunção com o objeto-valor almejado que inicialmente está em disjunção e o caminho percorrido por esta busca consistirá na narrativa do sujeito, o anti-sujeito será os obstáculos encontrados na busca pela conjunção. Em "Pântano de sangue" a disjunção consiste no desconhecimento dos motivos que acarretaram um assassinato, as ações se desenvolvem na busca pela conjunção que seria a compreensão do crime, o sujeito, que envereda por essa busca é um grupo de adolescentes e um investigador e o anti-sujeito são os criminosos, em especial, o chefe denominado com "Ent".

No entanto, segundo Fiorin (2000) esse modelo apresentava muitas limitações que conduziram a semiótica para uma segunda fase, na qual interessa-se pela competência modal do sujeito. $\mathrm{O}$ autor explica que "parte-se da constatação de que só pode executar uma ação quem possuir pré-requisitos para isso, ou seja, de que o fazer exige condições prévias. Só pode realizar uma ação o sujeito que quer e/ou deve, sabe e pode fazer" (FIORIN, 2000, p. 174). Desse modo, a doação de valores modais ao sujeito, capacitando-o para o agir é denominado como competência, enquanto que a apropriação desses valores e a ação desenvolvida pelo sujeito recebe o nome de performance. Logo, segundo Greimas e Courtés, "a semiótica é levada assim a construir modelos de competência modal que, baseados na análise dos discursos narrativos, são aplicáveis às semióticas não linguísticas do mundo natural e devem servir de premissas para uma semiótica da ação" (GREIMAS; COURTÉS, 2011, p. 76). Dessa forma, os autores denominam algumas especificidade de modalização: "a) o fazer modalizando o ser (a performance, o ato); b) o ser modalizando o fazer (competência); c) o ser modalizando o ser (modalidades veridctórias) e d) o fazer modalizando o fazer (modalidades factitivas) (GREIMAS; COURTÉS, 2011, p. 314).

Fontanille (2011) define que "as modalidades são predicados que atuam sobre outros predicados e, portanto, eles são predicados que modificam o estatuto de outros predicados. Ademais, eles asseguram uma mediação entre os actantes e seu predicado de base no interior de uma cena preditativa" (FONTANILLE, 2011, p. 169). Assim, por exemplo, a modalidade do querer 
ORTEGA, L.R.; FILHO, M.N.R.S.; SOUZA, A.C.S.

relaciona Crânio, um actante sujeito a um outro predicado, no caso desvendar (Crânio quer desvendar um crime).

Portanto, a partir desse momento, a semiótica passa a analisar com mais minúcias os tipos e os modos de existência do sujeito, o que possibilitou que além do estudo da ação, a investigar incidisse também sobre a manipulação, "do fazer ao fazer fazer" (FIORIN, 2000). Além de explicar a relação entre sujeito e objeto, passa-se a analisar as relações entre sujeitos, uma vez que "a manipulação se caracteriza como uma ação do homem sobre outros homens visando a fazê-los executar um programa dado" (GREIMAS; COURTÉS, 2011, p. 300). Para os autores, o sujeito destinador realiza uma proposta e por meio da persuasão convence o destinatário a aceitar. Esse estudo possibilita também a análise dos sujeitos manipulados que se submetem a esse processo ou 0 rejeitam.

Barros (2005) propõe um esquema que sintetiza as quatro classes de manipulação:

Quadro 1: Classes de manipulação

\begin{tabular}{|l|l|l|}
\hline & $\begin{array}{l}\text { Competência do destinador- } \\
\text { manipulador }\end{array}$ & $\begin{array}{l}\text { Alteração na competência do } \\
\text { destinatário }\end{array}$ \\
\hline PROVOCAÇÃO & $\begin{array}{l}\text { SABER (imagem negativa do } \\
\text { destinatário) }\end{array}$ & DEVER-FAZER \\
\hline SEDUÇÃO & $\begin{array}{l}\text { SABER (imagem positiva do } \\
\text { destinatário) }\end{array}$ & QUERER-FAZER \\
\hline INTIMIDAÇÃO & PODER (valores negativos) & DEVER-FAZER \\
\hline TENTAÇÂO & PODER (valores positivos & QUERER-FAZER \\
\hline
\end{tabular}

Fonte: BARROS, 2005, p. 35

As quatro classes de manipulação visam a alterar a competência do destinatário e para isso, como no caso da provocação, o destinador-manipulador manuseia o enunciado para transmitir a imagem negativa do destinatário e gerar a sensação do dever-fazer; ou então, constrói os enunciados com uma imagem positiva, seduzindo o destinatário a querer-fazer. Pode ainda se utilizar de valores negativos, no caso da intimidação e levar ao dever-fazer; ou valores positivos, como a tentação, para conduzir o destinatário ao querer-fazer. E assim, a manipulação estabelece a dimensão cognitiva da narrativa. Essa dimensão demonstra que a intersubjetividade é organizada por meio de estruturas polêmicas e contratuais. 
Por tratar das questões do estado da alma, a semiótica avança mais uma fase e passa a examinar a modalização do ser (BARROS, 2005). Os estudos das modalidades do fazer conduziram as buscas para as condições modais que seriam necessárias para que a ação se realizasse, uma vez que o sujeito de estado também pode ser modalizado, pois estabelece uma relação de conjunção com o objeto, favorecendo a modalização do ser. No caso da narrativa "Pântano de sangue", o sujeito-protagonista Crânio quer desvendar um crime, esse é o objeto desejável com o qual ele quer entrar em conjunção, nesse caso a modalização de estado incide sobre o valor que o sujeito atribui ao objeto e isso repercute sobre a existência modal do sujeito.

Retomando o percurso gerativo, " a semântica narrativa é o momento em que os elementos semânticos são selecionados e relacionados com os sujeitos" (BARROS, 2005, p. 44). Nesse caso, no interior dos enunciados de estado os elementos se instituem como valores, nos objetos. Segundo a autora, "a modalização de enunciado de estado é também denominada modalização do ser e atribui existência modal ao sujeito de estado" (BARROS, 2005, p. 44 - grifos da autora), enquanto que "a modalização de enunciados do fazer é, por sua vez, responsável pela competência modal do sujeito do fazer, por sua qualificação para a ação" (BARROS, 2005, p. 44).

Na modalização do fazer dois aspectos se destacam: o fazer-fazer que se refere ao "conjunto de modalidades factitivas que levam à ação" (FIORIN, 2000, p. 179), ou seja, o sujeito-destinador determina os valores modais que deverão ser executados pelo sujeito destinatário; e o ser-fazer como "as ações requeridas para realização da ação" (FIORIN, 2000, p. 179) que constitui a organização modal da competência do sujeito.

Na modalização do ser, as duas perspectivas que se destacam são: a relação do sujeito com o objeto que determina a verdade, a mentira, a falsidade ou o segredo de um enunciado de estado por meio da modalização veridictória; e as modalizações que recaem sobre os valores atribuídos ao objeto e são determinadas pelo querer, dever, poder e saber. Com relação as modalizações do fazer e do ser, para ampliar nossa compreensão, Fiorin (2000) apresenta o seguinte resumo: 
ORTEGA, L.R.; FILHO, M.N.R.S.; SOUZA, A.C.S.

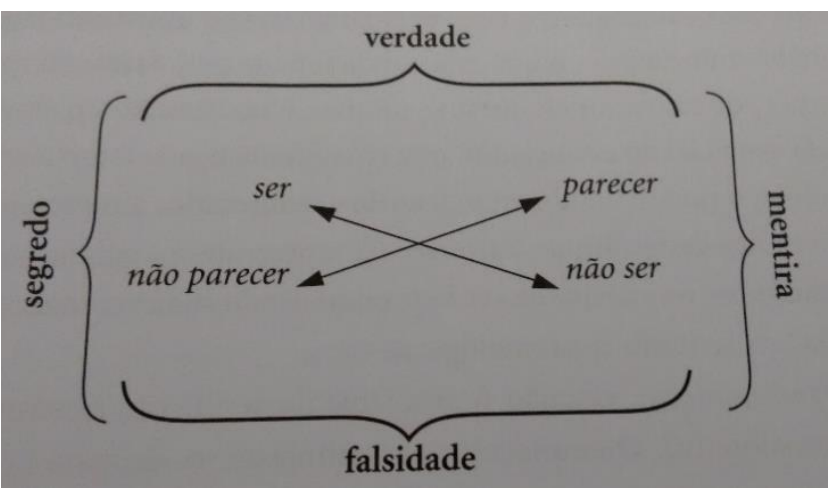

Fonte: Greimas; Courtés, 2011, p. 532
Temos então, as seguintes modalidades simples: fazer fazer, modalidades factitivas; ser ser: modalidades veridictórias, que articulam 0 ser e 0 parecer, estabelecendo a seguinte estrutura modal: ser + parecer = verdade; não ser + não parecer = falsidade; não ser + parecer $=$ mentira; não parecer + ser = segredo" (FIORIN, 2000, p. 180).

Para uma compreensão efetiva da obra em estudo aderimos a ótica de modalização do ser que incide sobre a relação de conjunção ou de disjunção que une sujeito e objeto, mais precisamente a modalidade veridictória e sobre isso discutiremos na próxima seção.

\section{A MODALIDADE VERIDICTÓRIA}

A semiótica greimisiana tem como preocupação situada no interior do discurso, o dizer-verdadeiro, ou seja, não o problema da verdade, mas o da veridicção que a partir da estrutura modal ser e parecer, possibilita ao enunciado se assumir como verdadeiro ou falso, como mentiroso ou secreto. Segundo Barros, "ser é o estatuto veridictório exposto pela própria narrativa ou, em outros termos, pelo narrador; parecer é o estatuto veridictório atribuído a um estado por uma personagem" (FIORIN, 2000, p. 176).

Um enunciado de estado pode ser capaz de modificar outro enunciado de estado, quando isso acontece, o primeiro constitui um enunciado modal que incide sobre a validade do segundo predicado, ou seja, sobre a relação de junção e assim temos o predicado modal. O predicado modal do ser é representado no quadrado semiótico da seguinte forma: 
Para Greimas e Courtés (2011), a categoria da veridicção é constituída por duas dimensões que agem no jogo da verdade: parecer/não parecer que é denominado como manifestação; e ser/não ser, como eminência. Esses esquemas conduzem a metatermos contrários ou contraditórios.

Dessa forma, temos a verdade, que segundo os autores, "designa o termo complexo que subsume os termos ser e parecer situados no eixo dos contrários no interior do quadrado semiótico das modalidades veridictória" (GREIMAS; COURTÉS, 2011, p. 529), ou seja, quando o discurso demostra o que é realmente, ser e parecer, temos a verdade. Porém, como contrariedade, se o discurso não é o que demonstra e também não parece ser, temos a falsidade, um "termo complexo que subsume os termos não ser e não parecer, situados no eixo dos subcontrários do quadrado semiótico das modalidades veridictórias" (GREIMAS; COURTÉS, 2011, p. 204). Importante lembrar, que segundo os autores, tanto o falso como o verdadeiro situam-se no campo do discurso, resultantes das operações de veridicção, portanto, não representam o mundo não discursivo, assim como a mentira e o segredo, não aludem a nenhuma relação referencial, mas são criados pelo próprio texto.

$\mathrm{Na}$ oposição do esquema, temos a mentira, na qual o que parece não corresponde à verdade, é o "termo complementar que subsume os termos não ser e parecer situados na dêixis negativa" (GREIMAS; COURTÉS, 2011, p. 305). $E$ ainda, quando o que é real não corresponde ao que parece, temos o segredo como "termo complementar que subsume os termos ser e não parecer situados na dêixis positiva" (GREIMAS; COURTÉS, 2011, p. 428). O suspense tão presente nos diversos gêneros literários, utiliza-se do esquema do segredo para desenvolver o enredo e aguçar a dúvida e a expectativa do leitor.

Com relação a obra Pântano de sangue de Pedro Bandeira, o segredo inicia-se com o assassinato do professor Elias, o que motiva o jovem Crânio a sair em busca de desvendar o crime, pois os indícios de assalto (Ele foi assassinado por causa de alguns trocados que trazia no bolso) afastavam a polícia da investigação de um assassinato premeditado e apenas o jovem enxergou ser o que não parecia, nem seus amigos, o grupo Karas, acreditavam nas desconfianças de Crânio que ligavam a morte do professor de matemática ao Pantanal mato-grossense. Com o desaparecimento do jovem Crânio no 
Pantanal, o mistério amplia-se e o grupo de jovens, Karas, junto com o investigador Andrade, seguem rumo ao Mato Grosso para desvendar esse enigma. O mistério é envolvido pelo crime organizado, pelo extermínio dos jacarés e dos indígenas, entre outros crimes que ampliam o suspense da narrativa e exigem das personagens e do leitor mais atenção e reflexão para desvendar o segredo. $O$ desfecho surpreendente revela a tia Matilde como a tesoureira do crime organizado internacional que guardava todo o ouro dos traficantes, então, o "não parecer" criminosa, escondia um "ser" chefe dos criminosos e suas descrições expostas tanto pelas personagens quanto pelo narrador desviavam a atenção de sua verdadeira identidade (Uma mulher alta e magra, toda vestida em cor-de-rosa... Deveria ter uns sessenta anos...Era aquela mulher cuja alegria e excentricidade tinham feito fama no Pantanal... Tudo era cor-de-rosa, tudo era fofo... Aquela velhinha valente... Parecia frágil, e abraçou o sobrinho...).

Os enunciados modalizados pela veridicção, também podem ser determinados pela modalidade epistêmica do crer, uma vez que, segundo Barros "um estado é considerado verdadeiro quando um sujeito, diferente do sujeito modalizado, o diz verdadeiro" (BARROS, 2005, p. 47), isto é, o sujeito destinatário acredita, crê, que o enunciado é verdadeiro, assim sendo, atribui a um enunciado um estatuto veridictório. De acordo com o Dicionário de semiótica,

o crer-verdadeiro do enunciador não basta, supomos, à transmissão da verdade: o enunciador pode dizer quanto quiser, a respeito do objeto de saber que está comunicando, que 'sabe', que está 'seguro', que é 'evidente'; nem por isso pode ele assegurar-se de ser acreditado pelo enunciatário: um crerverdadeiro deve ser instalado nas duas extremidades do canal da comunicação, e é esse equilíbrio, mais ou menos estável, esse entendimento tácito entre dois cúmplices mais ou menos conscientes que nós denominamos contrato de veridicção (ou contrato enunciativo) (GREIMAS; COURTÉS, 2011, p. 530 grifos dos autores).

Segundo os autores, o dizer-verdadeiro não depende apenas do sujeito enunciador, o enunciatário é o responsável pela decisão do ser ou não ser, logo, ambos são responsáveis para o bom desenvolvimento do contrato de veridicção. Para Barros, "parte-se do parecer ou do não-parecer da manifestação e constróise ou infere-se o ser ou o não-ser da imanência" (BARROS, 2005, p. 47), por 
ORTEGA, L.R.; FILHO, M.N.R.S.; SOUZA, A.C.S.

isso, relaciona-se com o fazer interpretativo e à manipulação do sujeito destinador. Desse modo, o enunciador pode não apresentar a verdade, mas fazer parecer verdadeiro, pois, precisa convencer seu interlocutor por meio de um fazer persuasivo para que este estabeleça uma adesão ao enunciado e contribua com o seu fazer interpretativo. Sobre isso Greimas e Courtés asseveram:

\begin{abstract}
Exercido pelo enunciador, o fazer persuasivo só tem uma finalidade: conseguir a adesão do enunciatário, o que está condicionado pelo fazer interpretativo que este exerce, por sua vez: pelo mesmo motivo, a construção do simulacro de verdade, tarefa essencial do enunciador, está igualmente ligada tanto a seu próprio um universo axiológico quanto ao do enunciatário e, sobretudo, à representação que o enunciador se faz deste último universo (GREIMAS; COURTÉS, 2011, p. 531).
\end{abstract}

Para os autores, o fazer-crer e o crer verdadeiro são procedimentos sintáticos manifestados no nível do discurso que dependem de enunciador e enunciatário na fixação de um acordo implícito que resultam nos modos de veridicção: a verdade, a falsidade, a mentira e o segredo.

No que se refere mais especificamente ao contrato enunciativo entre enunciador e enunciatário, Fiorin (2008) aprofunda os estudos sobre a questão da veridicção e estabelece quatro tipos de contratos que o enunciador pode se utilizar para conquistar a confiança do enunciatário, são eles: o contrato objetivante, o contrato subjetivante, o contrato semiótico e o contrato metalinguístico.

De acordo com Fiorin (2008), o contrato objetivante se funda na realidade, "nele, concebe-se que, na relação entre sujeito e objeto, isto é, homem e mundo, o segundo elemento impõe-se sobre o primeiro" (FIORIN, 2008, p. 203), por isso, aqui temos o narrador em terceira pessoa.

No contrato subjetivante, o narrador pode aparecer em primeira ou em terceira pessoa, porém com predomínio em primeira pessoa, já que os fatos são relatados por um "eu" e não se narram a si mesmo, pois, "se pensa que o mundo só é cognoscível por meio da subjetividade humana, que o texto representa o mundo, mas essa representação só pode ser feita pela subjetividade humana" (FIORIN, 2008, p. 203). As ações das personagens são guiadas pelo 'coração' e todo o enredo demonstra a subjetividade do narrador. 
O terceiro contrato é denominado por Fiorin (2008) como semiótico, pois "parte do pressuposto de que a relação homem/mundo não se faz diretamente, mas de que é mediada pela linguagem" (FIORIN, 2008, p. 206). Nesse caso, para o autor, o signo é o resultado da união entre um plano de conteúdo e um plano de expressão, não é o representante dos processos do mundo, refere-se a um conteúdo linguístico, já que a linguagem não é a representação clara da realidade, mas cria diferentes realidades e assim dá forma ao mundo. O narrador é sempre em primeira pessoa, uma vez que, "a verossimilhança, nesse tipo de contrato, é uma construção interna à obra e não uma adequação ao referente" (FIORIN, 2008, p. 209), e assim, "narrador e personagens não são pessoas do mundo, mas criações da linguagem. A verdade não é vista numa concepção empírica [...] mas como uma construção da linguagem" (FIORIN, 2008, p. 209).

Por fim, o contrato metalinguístico, que segundo o autor, "pensa a realidade como discurso e o embate se dá entre discursos" (FIORIN, 2008, p. 216), assim sendo, concebe a linguagem como realidade ligada aos processos sociais. Nesse contrato há o espaço para a paródia, ou seja, o processo que inverte o sentido do texto no processo de construção do mesmo.

O tipo de contrato entre enunciador e enunciatário influencia a modalidade veridictória que predomina no texto. Assim, na próxima seção aprofundaremos nossas reflexões sobre o segredo, logo, sobre o suspense que mobiliza a atenção do leitor do início ao fim da narrativa.

\section{O SUSPENSE}

Para que aja suspense é preciso preservar um segredo, uma zona escura de incertezas, na qual, o leitor sabe apenas o que o narrador deseja que ele saiba, pois "o suspense relaciona-se sempre com a resolução de um mistério, algo imerso na obscuridade, um enigma esfíngico" (SILVA, 2011, p. 154).

Roland Barthes (1992) em sua obra S/Z, desenvolve um admirável estudo sobre o suspense e demonstra que o enigma e sua resolução referem-se a uma questão e a uma resposta, esta última só é apresentada, normalmente, no final da obra. Segundo o autor, os mecanismos do suspense dependem de um "conjunto das unidades que tem como função articular, de diversas maneiras, uma pergunta, sua resposta e os diversos acidentes que podem ou preparar a 
pergunta ou retardar a resposta; ou ainda: formular um enigma e ajudar a decifráIo" (BARTHES, 1992, p. 50), especialmente utilizando o recurso da mentira ou o fingimento que fazem com que a resposta seja ainda mais retardada e o enigma, mais difícil de ser decifrado. Nesse contexto, as virtualidades se ampliam a partir de um único segredo e os movimentos de manipulação conduzem os destinatários a interpretações puramente especulativas, gerando a chamada tensão narrativa.

O Dicionário de semiótica, apresenta como termo similar a suspense, a palavra suspensão e a define da seguinte forma:

\begin{abstract}
para a semiótica, a suspensão surge como um dos "propulsores dramáticos" do discurso narrativo [...] a suspensão da modalização epistêmica faz surgir, num momento dado, um fazer informativo neutro, provocando assim uma inquietação no enunciatário, abandonado na ignorância do estatuto veridictório do saber recebido [...] o da isotopia do secreto [...] a dificuldade reside no reconhecimento das marcas do secreto [...] da alusão que insinua que o não parecer esconde pelo menos um ser: é evidente que sem essas maras o secreto não existira (GREIMAS; COURTÉS, 2011, p. 491).
\end{abstract}

Para os autores, o suspense ou suspensão impulsiona a narrativa, deixando-a mais atrativa, pois incita as emoções do leitor por meio da dúvida e do desejo de desvendar o segredo que lhe é apresentado, de descobrir o ser que está escondido em um não parecer. Em nossa obra em estudo, durante a investigação pelo Pantanal Mato-grossense, ocorrem várias insinuações de que o comandante das forças federais denominado de senador pudesse ser o chefe dos criminosos disfarçado, até mesmo sua voz alta e grosso e seu físico muito grande indicavam agressividade (O vozeirão daquele enorme homem... $\mathrm{O}$ senador ficou subitamente ansioso... O senador não parecia muito feliz com aquela companhia - o tenente...) e ainda os slides do professor Elias desapareceram em sua fazenda. Esse era o saber recebido pelo leitor, que buscava afastá-lo do secreto, mas na verdade, apesar de não ter as características de um policial e parecer um criminoso, o senador realmente estava do lado da lei, era quem dizia ser mesmo que não parecesse.

Assim, o suspense inverte a orientação normal dos acontecimentos, por isso surge como modalizador entre o conhecido e o desconhecido, segundo Limoli e Teixeira, como "ponto de intersecção entre, de um lado, algo que se apresenta como rotineiro, cotidiano; como monotonia dos fatos ou, pelo menos, 
a indiferença por eles provocada; e, de outro lado, a irrupção súbita de uma nova articulação de eventos" (LIMOLI; TEIXEIRA, 2014, 109), portanto, pode transformar a rotina em acontecimento inusitado.

O suspense, em termos narrativos, pode transmitir comunicações com atrasos e esconder as informações que levariam a resolução do mistério, tratando-se de apresentar inúmeros obstáculos para compreensão do segredo. Essa característica do suspense, afeta o destinatário, possibilitando sua participação na produção de sentido, embora, muitas vezes se tenha a sensação de impotência diante da obscuridade da narrativa, já que "a reticência textual na qual se constitui o suspense aguça a curiosidade do intérprete, implicando-o na história que se desenrola diante dele, prendendo-o passionalmente na incerteza, ainda que provisória (LIMOLI; TEIXEIRA, 2014, 111). A narrativa Pântano de sangue tem suas interrupções textuais constantes, pois a narração muda de uma cena a outra exigindo total atenção do leitor, ao mesmo tempo que amplia as dúvidas e questiona as certezas dos enunciatários.

O passional tem sua origem no ser, ou seja, nas variações dos estados do sujeito, por isso vincula-se às relações que definem sua existência modal, assim sendo, são as relações existenciais entre o sujeito e o objeto que passam a ser analisadas. Segundo Fiorin (2000) à quarta fase da semiótica trata dessa passionalidade, ou seja, trouxe um fecundo estudo das paixões que é entendida, segundo o autor, " como efeitos de sentido de qualificações modais que alteram o sujeito de estado, o que significa que é vista como um arranjo das modalidades do ser, sejam elas compatíveis ou incompatíveis" (FIORIN, 2000, p. 177). Para esclarecer essa definição, o autor apresenta o exemplo da obstinação e da docilidade, no qual, a primeira é o resultado de um querer ser limitado por um não poder ser, enquanto a segunda, apenas um querer ser o que pode ser.

Para Fontanille, "a semiótica das paixões nasceu da necessidade de resolver heterogeneidades próprias à semiótica narrativa, na qual - ao lado dos enunciados de junção e de suas transformações - surgem [...], de uma forma geral, afetivos" (FONTANILLE, 2011, p. 204). Logo, a semiótica passa a estudar a modalidade afetiva do sujeito, e seu trajeto de emoções durante a narrativa.

A semiótica, então, focalizou em suas análises, o arranjo modal das narrativas que caracterizam as denominações das paixões como amor, ansiedade, medo ou horror entre outros. Considera-se que o sujeito segue um 
percurso na narrativa e muda suas posições passionais, passando de um estado a outro, pois se define pela modalização de seu ser, por isso "o exame das paixões, sob a forma de percursos modais, explica a organização semântica da narrativa, ou seja, os 'estados de alma' dos sujeitos, modificados no desenrolar da história" (BARROS, 2005, p. 52). Assim sendo, o sujeito é suprido por uma carga modal e essas modalidades que podem ser compatíveis, contrárias ou contraditórias, determinam o percurso do sujeito na narrativa.

Segundo Limoli e Teixeira (2014), como leitores, não temos como fugir às emoções provocadas pelo objeto-texto e respondemos passionalmente a esses estímulos, e assim nos apiedamos de um personagem que sofre, "ou de outro que nos provoca a ira ou a inveja, e desse modo desejamos que desapareça da história; [...] Não importa se os fatos são verdadeiros ou inventados, toda narrativa desperta pelo menos uma paixão mesmo que ela se chame indiferença (LIMOLI; TEIXEIRA, 2014, p. 106).

Considerando em particular o caso do suspense, a paixão que irá dominar os enunciados será a ansiedade, ou seja, um "estado afetivo penoso, caracterizado pela expectativa de algum perigo que se revela indeterminado e impreciso, e diante do qual o indivíduo se julga indefeso" (Houass, 2009). Portanto, nas narrativas de suspense, o enunciatário é tomado por esse sentimento que chega a caracterizar uma tortura psicológica. De acordo com Silva,

a paixão da ansiedade é um recurso que o enunciador elege para atingir o estado emocional do enunciatário, visto que somente a ele é dado um saber que o diferencia da ignorância relativa ao ator discursivo, o que induz o enunciatário a uma tomada de consciência do estado emocional da ansiedade como resultado da estratégia do enunciador do suspense (SILVA, 2011, p. 218).

Desse modo, o enunciador utiliza-se de recursos para incitar a ansiedade do receptor, como revelar-lhe alguma parte do segredo ainda ignorada pelos demais participantes da trama. Para o autor, as emoções oscilam durante 0 enredo, inicialmente, vai do relaxamento à tensão e depois da tensão ao relaxamento. A tensão inicia-se com a aflição, ao ser intensificada torna-se angústia e seu ponto máximo chega ao suplício antes de retornar ao relaxamento. 
Podemos exemplificar esses momentos de tensão por meio de uma das personagens de Pântano de sangue, o detetive Andrade: a personagem é tomada pela aflição quando sabe do desaparecimento do jovem Crânio, a angústia the acomete quando ele e mais dois jovens são aprisionados pelos criminosos do Pantanal. Mas é no momento em que os criminosos tiram a personagem feminina, Magrí, de junto dos prisioneiros é que o suplício se instala por meio do choro desesperado do detetive.

Por tudo isso, o suspense é caracterizado pela espera, pela ansiosa espera do inesperado, que segundo Silva, "é a espera dilatada de que algo, iminente ou tardio, aconteça" (SILVA, 2011, p. 78). Para o autor, é essa espera que mantém o suspense e transmite a impressão de algo interminável, por isso é o aspecto que desperta e mantém o interesse do destinador.

Para isso, o enunciatário pode se utilizar de um único fato que cresce durante a narrativa intensificando o enigma, ou provocar o suspense por meio da inserção de vários fatos. Em Pântano de sangue, o suspense instala-se com o brutal assassinato do professor Elias, os demais fatos inseridos compõem os obstáculos para que esse crime seja desvendado e ampliam a ansiedade. Pode ainda, esconder algo das personagens e dos leitores, conduzindo a expectativa até o final, ou ainda, revelar aos leitores informações desconhecidas pelas personagens, ampliando a tensão a cada ação das personagens. Em relação à Pântano de sangue, os leitores sabem que Crânio está vivo e conhecem sua trajetória pelo Mato Grosso, porém as demais personagens desconhecem seu paradeiro, até mesmo se está vivo, isso faz com que além da ansiedade, o leitor queira interferir na narrativa, sinta angústia quando as pistas levam à direção contrária, queira informar, ajudar, mas sente-se impotente, porém, tanto personagens quanto leitores desconhecem a identidade do assassino e as razões que ocasionaram o crime durante o desenvolvimento do enredo para que o segredo seja preservado até o desfecho da narrativa.

A espera, então, fundamenta o suspense, e o inesperado contamina a narrativa, para Silva, "a espera do inesperado fundamenta-se em fraturas que têm por objetivo romper com a simetria" (SILVA, 2011, p. 81). Durante toda a espera em Pântano de sangue, nenhuma suspeita incidiu sobre a tia Matilde, tão excêntrica e amada por todos, a revelação de que era ela a grande chefe dos criminosos foi a concretização do inesperado. 


\section{CONSIDERAÇÕES FINAIS}

A semiótica como ciência da linguagem foi aprofundando fases para analisar e compreender a composição e organização dos textos literários. Nesse sentido, a modalidade veridictória contribui para a compreensão de como os enunciados de estado são modalizados para refletirem a verdade, a falsidade, a mentira ou o segredo.

Por meio da teoria da modalização do ser refletimos como a obra Pântano de sangue de Pedro Bandeira foi organizada para instituir o suspense e aguçar a curiosidade dos leitores, construindo o segredo a partir do não parecer e ser na identidade de alguns personagens e em algumas cenas.

Constatamos que a obra é apropriada para jovens leitores, pois explora a paixão da ansiedade intensificando o segredo. E ainda, pode ser estudada pelo viés da semiótica, por meio da modalidade veridictória como forma de ampliar as compreensões e promover a reflexão sobre a composição.

\section{REFERÊNCIAS}

BANDEIRA, Pedro. Pântano de sangue. 5. ed. São Paulo: Moderna, 2014.

BARROS, Diana Luz de. Teoria semiótica do texto. 4. ed. São Paulo: Editora Parma, $2005 . \quad$ Disponível em https://drive.google.com/file/d/OB2wn2mmgpSR8OUFpQmJxUzVJZWs/edit

BARTHES, R. S/Z. Rio de Janeiro: Nova Fronteira, 1992. Disponível em http://monoskop.org/images/d/d6/Barthes_Roland_S-Z_2002.pdf

EAGLETON, Terry. Teoria da literatura: uma introdução. Tradução de Waltensir Dutra. 6. ed. São Paulo: Martins Fontes, 2006.

GREIMAS, A. J.; COURTÉS, J. Dicionário de semiótica. 2. ed. São Paulo: Contexto, 2011.

FIORIN, José Luiz. Modalização: da língua ao discurso. Alfa, São Paulo, 2000. p. 171-192.

A crise da representação e o contrato de veridicção no romance. Revista do Gel. São José do Rio Preto, v. 5, n. 1, 2008, p. 197-218.

FONTANILLE, Jacques. Semiótica do discurso. Tradução: Jean Cristtus Portela. São Paulo: Contexto, 2011. 
HOUAISS, Instituto Antônio. Houaiss eletrônico - versão monousuário 3.0. Rio de Janeiro: Objetiva, junho de 2009.

LIMOLI, Loredana. Atualização narrativa, paixão e suspense na telenovela. In: CORTINA, Arnaldo; SILVA, Fernando Moreno da (Orgs.). Semiótica e comunicação: estudo sobre textos sincréticos. Araraquara/SP: Cultura Acadêmica, 2014, p. 143-168.

LIMOLI, Loredana; TEIXEIRA, Lucia. O suspense nas frisadas da Avenida Brasil. CASA: Cadernos de Semiótica Aplicada, v. 12, n. 1, 2014, p. 101-136.

SILVA, Fernando Moreno da. MODALIZAÇÃO: teoria e aplicação. Revista Prolíngua - ISSN 1983-9979. Volume 2 Número 2 - Jul./Dez. de 2009. p.48-56.

SILVA, Odair José da. O suplício na espera dilatada: a construção do gênero suspense no cinema. Tese (Doutorado em Semiótica e Linguística Geral). Faculdade de Filosofia, Letras e Ciências Humanas da Universidade de São Paulo. São Paulo, 2011.

\section{Como citar este artigo (ABNT)}

ORTEGA, L.R.; FILHO, M.N.R.S.; SOUZA, A.C.S. A modalidade Veridictória na articulação do suspense. SELL, Uberaba, MG, v. X, n. X, p. XXX-XXX, 2019. Disponível em: <inserir link de acesso>. Acesso em: inserir dia, mês e ano de acesso. DOI: inserir link do DOI.

Como citar este artigo (APA)

Ortega, L.R., Filho, M.N.R.S. \& Souza, A.C.S (2019). A modalidade Veridictória na articulação do suspense.SELL, X (X), XXX-XXX. Recuperado em: inserir dia, mês e ano de acesso de inserir link de acesso. DOI: inserir link do DOI. 